\title{
Marion Denizot, Le "Théâtre de la Révolution" de Romain Rolland. Théâtre populaire et récit national
}

\section{Paola Perazzolo}

\section{(2) OpenEdition}

1 Journals

\section{Edizione digitale}

URL: http://journals.openedition.org/studifrancesi/587

DOI: 10.4000/studifrancesi.587

ISSN: 2421-5856

\section{Editore}

Rosenberg \& Sellier

\section{Edizione cartacea}

Data di pubblicazione: 1 aprile 2015

Paginazione: 189

ISSN: 0039-2944

\section{Notizia bibliografica digitale}

Paola Perazzolo, "Marion Denizot, Le "Théâtre de la Révolution" de Romain Rolland. Théâtre populaire et récit national », Studi Francesi [Online], 175 (LIX | I) | 2015, online dal 01 avril 2015, consultato il 18 septembre 2020. URL : http://journals.openedition.org/studifrancesi/587 ; DOI : https://doi.org/ 10.4000/studifrancesi.587

Questo documento è stato generato automaticamente il 18 settembre 2020.

\section{(c) (i) $\odot$}

Studi Francesi è distribuita con Licenza Creative Commons Attribuzione - Non commerciale - Non opere derivate 4.0 Internazionale. 


\title{
Marion Denizot, Le "Théâtre de la Révolution" de Romain Rolland. Théâtre populaire et récit national
}

\author{
Paola Perazzolo
}

\section{NOTIZIA}

MARION DENIZOT, Le "Théâtre de la Révolution" de Romain Rolland. Théâtre populaire et récit national, Paris, Champion, 2013 («Littérature de notre siècle», 47), pp. 289.

1 Esperta di studi teatrali i cui campi di ricerca vertono soprattutto sulla storia delle politiche e delle istituzioni teatrali, sull'eredità del teatro popolare e sulla rappresentazione drammatica della storia, nel presente volume Denizot coniuga questi suoi interessi analizzando l'opera di Romain Rolland come un «phénomène social total» (p. 9) di cui è importante evidenziare i legami esistenti tra teatro e contesto socioculturale, rappresentazioni mentali, sistema di valori e pratiche culturali. Nella prima parte del volume l'A. prende infatti in considerazione, oltre a Le Théâtre du Peuple - il più noto contributo teorico dell'artista - anche la corrispondenza, i diari, e il ciclo drammatico - ancora molto poco rappresentato e altrettanto poco studiato - del Théâtre de la Révolution, composto da otto pièces scritte tra il 1898 et il 1938. La seconda parte verte sull'analisi della ripresa, nel 1936, de Le Quatorze Juillet di Gémier, ripresa che segna l'esplicitazione del legame ideale e ideologico esistente tra il teatro popolare di fine XIX secolo, il Front Populaire e il suo programma politico per un teatro che si vuole, appunto, popolare, e il pensiero di Rolland che tuttavia - così come esplicitato nella terza parte del lavoro - non risulta esente da ambiguità e contraddizioni relativamente al rapporto con la produzione dell'epoca e a quello con il popolo, ideale destinatario della rappresentazione.

2 Ancora relativamente misconosciuta, l'opera di Rolland viene qui contestualizzata dal punto di vista estetico e storico ed esaminata nella sua unicità al fine di meglio 
comprendere come Le Théâtre de la Révolution si inserisca non solo nel filone del teatro popolare ma anche nel movimento di democratizzazione della cultura della prima metà del secolo scorso. Ad un livello più "epidermico", l'A. evidenzia la concretizzazione di numerosi enjeux del teatro popolare - la presenza in scena del popolo, la semplicità dell'azione drammatica, il costante confronto dell'individuale e del collettivo. Ad un livello più profondo, lo studio mostra come il pensiero di Rolland si riallacci al movimento del teatro popolare in quanto fondato su una concezione unica della nazione e sull'idea vitalistica e idealistica di un'arte, quella teatrale, finalizzata al rinnovamento di una società decadente. Per Denizot, l'opera in questione non solo si presenta «comme l'expression d'une vision singulière du monde, fondée sur la foi en l'Homme, et dans le même temps, comme le fruit d'un contexte historique, qui s'efforce de refonder l'unité nationale» (p. 252), ma trova nella Rivoluzione francese un riferimento quasi obbligato. Il ricorso alle istanze e agli avvenimenti rivoluzionari appare quindi non solo come la tensione verso la ricerca - a livello di estetica drammatica così come di visione del mondo - delle premesse di un'arte veramente nazionale e «popolare», ma anche come una matrice funzionale a spiegare e riconsiderare evoluzioni storiche coeve quali l'impennata nazionalista della fine del XIX secolo, le lotte per la supremazia in Europa durante la prima guerra mondiale, l'ascesa di regimi autoritari in URSS e in Europa tra gli anni Venti e Trenta. 